\section{Asset Mispricing, Arbitrage, and Volatility}

\author{
William R. Emmons and Frank A. Schmid
}

$\triangle 1$ fter nearly four decades, academic economists continue to debate financial-market efficiency as vigorously as ever. ${ }^{1}$ The original theoretical arguments put forward in favor of efficient markets were based on the notion of stabilizing speculation in the form of arbitrage (Friedman, 1953). Simply put, arbitrage is "the simultaneous purchase and sale of the same, or essentially similar, security in two different markets for advantageously different prices" (Sharpe and Alexander, 1990). In theory, a perfectly hedged trading position of this sort could be executed at no cost (as the short-sale proceeds are used to finance the long position). Vigilant traders on the look-out for just such arbitrage opportunities would ensure that no one could consistently "beat the market" - the hallmark of efficient markets theory.

The academics' logical case for efficient markets boils down to a pair of simple rhetorical questions: Why would utility-maximizing traders leave unexploited any profitable opportunities (after adjusting properly for risk)? And if no risk-adjusted "free lunches" exist, how could market prices be predictable enough to make money? For several decades, empirical evidence piled up both for and against market efficiency. As of the early 1990s, neither side could claim total vindication. As the 1990s progressed, however, the weight of the evidence seemed to tip toward those who claimed asset prices were, at least to some extent, predictable (Campbell, Lo, and Mackinlay, 1997, Chaps. 2 and 7).

The academic asset-pricing literature today is dominated by attempts to explain why and to what extent the price movements of financial assets are predictable. One potential explanation of stockreturn predictability is that markets are efficient ("no free lunch") but expected returns are timevarying, perhaps being linked to the business cycle. For example, expected returns may be highest when economic risks are perceived to be high, such as at or near the bottom of a business cycle. Conversely,

William R. Emmons is an economist and Frank A. Schmid is a senior economist at the Federal Reserve Bank of St. Louis. William V. Bock provided research assistance.

(C) 2002, The Federal Reserve Bank of St. Louis. expected returns may be lowest when economic risks are perceived to be low, at or near a businesscycle peak. Thus, the simple random-walk model of stock returns may be false, but a relevant notion of market efficiency survives because high returns are earned only by taking large amounts of risk. A different type of explanation of return predictability rejects market efficiency and focuses on market imperfections of various sorts, such as incomplete stock-market participation by households, significant transactions costs, changes in investor sentiment, or limited wealth and liquidity resources to conduct arbitrage (as in the current article). ${ }^{2}$

Whatever its economic explanation, mounting evidence of return predictability leads Campbell, Lo, and Mackinlay (1997, p. 24) to suggest that it is time for financial economists to focus their attention on the "relative efficiency" of a market instead of continuing the all-or-nothing battle of attrition that is characteristic of much of the earlier market efficiency literature.

As we now understand more clearly, the original case for efficient markets probably leaned too heavily on the notion of risk-free, cost-free arbitrage to eliminate all profitable trading strategies immediately. In real markets, arbitrage is neither as easy nor as effective as economists once had assumed. For one thing, financial markets are not complete and frictionless, so arbitrage in general is risky and costly. In addition, it is not realistic to assume that the number of informed arbitrageurs or the supply of financial resources they have to invest in arbitrage strategies is limitless.

This article builds on an important and insightful recent model of arbitrage by professional traders who need - but lack - wealth of their own to trade (Shleifer and Vishny, 1997). Professional arbitrageurs must convince wealthy but uninformed investors to entrust them with investment capital in order to exploit mispricing and push the market back toward the ideal of efficiency. Unfortunately, arbitrageurs cannot prove that they recognize the intrinsic (or "fundamental") values of the assets they claim are mispriced. Even worse, it is possible the assets will

\footnotetext{
1 For early statements of the theory of efficient markets and the unpredictability of asset-price movements, see Fama (1965), Muth (1960), or Samuelson (1965). For a recent summary of the evidence for return predictability and its implications for efficient-markets theory, see Campbell, Lo, and MacKinlay (1997, Chap. 2).

2 Ironically, Keynes (1936, Chap. 12) clearly foreshadowed the recent interest in investor sentiment and liquidity for understanding stock market behavior, but was forgotten for decades as the efficient-markets hypothesis dominated the academic discussion.
} 
become even more mispriced before reverting eventually to their intrinsic values. Having incurred losses, the outside investors may demand their money back at this point even though the expected profit of staying invested actually has increased.

Thus, market efficiency may depend ultimately on the successful resolution of a principal-agent problem that exists between informed but wealthconstrained arbitrageurs and uninformed wealthy investors. The resulting degree of market efficiency may change over time and differ across markets, and it could depend importantly on factors such as the outside investors' use of performance-based ("feedback") strategies when deciding on the possible termination of ongoing investment mandates.

After developing a simple model of wealthconstrained professional arbitrage that departs in several important aspects from the canonical Shleifer and Vishny (1997) model, we calibrate our model to illustrate its qualitative features. We show that the existence of professional arbitrageurs mitigatesbut cannot eliminate-mispricing in the market relative to intrinsic values, regardless of how sensitive the outside investors are to arbitrageurs' past performance in deciding whether to remain invested with them. We also show that arbitrage dampens the unconditional volatility of asset returns, which we measure as the expected value of squared returns. Most importantly, the presence of arbitrageurs limits both the degree of increased mispricing and level of volatility during a financial crisis, which we define as a period of heightened volatility and acute shortage of liquidity. ${ }^{3}$ This result points out that professional arbitrageurs tend to stabilize markets even when they are wealth-constrained. Other papers show that investors who use "positive feedback" trading strategies-such as portfolio insurers-tend to destabilize markets (Grossman and Zhou, 1996).

We analyze a three-date (two-period) model of an aspiring professional arbitrageur (or "convergence trader" in the language of Kyle and Xiong, 2001, and Xiong, 2001) who must obtain financing from investors less informed than he is about the intrinsic value of a financial asset - that is, its liquidation value at the end of the second period. In addition to these two types of individuals, there are noise traders who have wealth to invest but who misperceive the asset's intrinsic value. It is the noise traders who drive the asset's price away from the intrinsic value.

The investors provide the arbitrageur with funds to invest in an underpriced asset at the outset of the model. The price is observed again at the end of the first period, at which time the investors may "roll over" their funds with the arbitrageur or demand their money back if they have lost confidence in his ability. The asset will assume its intrinsic value at the end of the second period with certainty, although only the arbitrageur knows in advance what that value is. Consequently, the two-period return on the arbitrageur's private information would be both positive and risk-free if he could be assured of financing.

Our set-up highlights the fact that a two-period risk-free arbitrage nevertheless can be risky over a one-period horizon in the presence of noise traders and financial constraints on the arbitrageur. The risk arises because the arbitrageur needs outside investors, and these outside investors might revise their beliefs about the arbitrageur's talent at the interim date, based on the return the arbitrageur achieved in the first period. If the investors downwardly revise their beliefs about the arbitrageur's abilities because the fund lost money due to a deepening of the mispricing, they might withdraw their money precisely when the expected return on the arbitrage is at its maximum. One implication is that the arbitrageur will invest "strategically" - that is, he will not invest as much initially as he would in a world without wealth constraints-in order to hedge against the possibility of being unable to exploit even greater mispricing should it occur one period ahead. Of course, this is not a new finding; for papers with similar results, see Grossman and Vila (1992), Shleifer and Vishny (1997), or Gromb and Vayanos (2001). ${ }^{4}$ Our paper's contributions in this respect

\footnotetext{
3 Myron Scholes (2000) suggests that the global financial crisis of 1997 98 was characterized by an increase in volatility, especially in equity markets, and a flight to liquidity (that is, a preference by many investors for assets whose liquidity was expected to be good). The crisis was accentuated by the "negotiated bankruptcy" of Long-Term Capital Management (LTCM), a hedge fund in which Scholes himself was a partner. According to Scholes, prior to the crisis, LTCM "was in the business of supplying liquidity" and therefore its demise worsened the crisis by eliminating the liquidity it had been supplying. A theoretical analysis relevant to this episode is Xiong (2001).

4 The first rigorous investigations of the multi-period investment problem were Merton (1971, 1973) and Breedon (1979). Merton concluded that a trader should keep a constant fraction of his wealth invested in the risky asset at all times. The fraction depends on the asset's expected return and risk and the investor's degree of risk aversion. Grossman and Vila (1992) added leverage and solvency constraints to the dynamic trader's problem. Their trader optimally commits more wealth to the risky asset the shorter is the investment horizon and the further from the leverage constraint (not just today but prospectively in the future) the trader finds himself. Campbell and Viceira (1999) is a recent examination of the problem under the assumption that the investor is aware that the probability distributions from which asset returns are drawn change over time.
} 


\section{Figure 1}

\section{Timeline of the Model}

$\begin{array}{ccc}t_{1} & t_{2} & t_{3} \\ \begin{array}{c}\text { Noise traders' } \\ \text { misperception, } S_{1}, \\ \text { in place. }\end{array} & \begin{array}{c}\text { Noise traders' } \\ \text { misperception } \\ \text { might deepen to } S_{2} .\end{array} & \begin{array}{c}\text { Noise traders' } \\ \text { misperception } \\ \text { corrects }\left(S_{3}=0\right) .\end{array} \\ \begin{array}{c}\text { Arbitrageur allocates } \\ \text { financial resources } \\ \text { If asset and cash. }\end{array} & \begin{array}{c}\text { Hedge fund } \\ \text { to intrinsic value, } V,\end{array} & \text { winds down. } \\ \text { arbitrageur liquidates. }\end{array}$

are a more realistic objective function for the arbitrageur and a set-up in which the arbitrageur's trading significantly affects the asset's price. Our model generates interior solutions and we provide calibrated illustrations of the model's results. While Shleifer and Vishny (1997) assume that the arbitrageur maximizes assets under management, we assume that he maximizes his income. The arbitrageur's income is determined by an incentive scheme that resembles real-world contracts of hedge fund managers.

\section{THE MODEL}

There are three types of agents in the model. Noise traders have wealth but misperceive the intrinsic value of a financial asset. Professional arbitrageurs have no wealth or borrowing capacity but know the intrinsic value of the financial asset. Investors have wealth but no insight into the financial asset's intrinsic value. Unlike noise traders, investors know that they cannot recognize the asset's intrinsic value. All parties are risk-neutral.

The investors may provide the arbitrageur with funds to invest in an underpriced asset at the outset of the model (see Figure 1). We refer to this arrangement as a hedge fund. Noise traders misperceive the intrinsic value of at least one financial asset in the economy, which generates arbitrage opportunities that so-called "long-short" investment strategies seek to exploit. Asset mispricing implies that there are relatively overpriced and relatively underpriced assets, which means that a portfolio that is long on the relatively undervalued asset and short on the relatively overvalued asset trades below intrinsic value.

We treat a market-neutral long-short portfolio as a single, complex financial asset. Arbitrage is the process of acquiring a long-short portfolio and holding it until its price returns to the portfolio's intrinsic value. The long-short portfolio that any arbitrageur might hold defines a market segment of a larger arbitrage industry. We assume that arbitrageurs are highly skilled people who pursue proprietary trading strategies and therefore enjoy a monopoly in their segment. For simplicity only, we make the assumption that the operating costs in the arbitrage industry are zero.

The risk-free rate of return, and therefore the opportunity cost of capital, is zero. For simplicity, we assume that risky assets trading at fair valueincluding the stock market index-also have an expected return of zero. This implies that there are no priced systematic risk factors in the economy, that is, there is no equity risk premium.

The asset trades at three moments in time, $t$ $(t=1,2,3)$. We capture the influence of the noise traders' misperceptions of the intrinsic value of the asset at times $t_{1}$ and $t_{2}$ with the parameters $S_{1}$ and $S_{2}$, respectively. There is no fundamental risk in the model because the price of the asset will revert to the intrinsic value at a known date $\left(t_{3}\right)$ with certainty (so $S_{3}=0$ ).

The supply of the financial asset is unity. Noise traders' demand for the financial asset at time $t$ $(t=1,2,3)$ is expressed as

$$
Q N_{t}=\frac{V-S_{t}}{p_{t}}, 0 \leq S_{t}<V
$$

where $p_{t}$ is the price of the financial asset and $S_{t}$ is the misperception of the noise traders about the intrinsic value of the financial asset. Because the financial asset in question is a long-short portfolio whose value is underestimated by the noise traders, the noise traders demand less than one unit of the 
financial asset. Without misperception $(S=0)$, the noise traders would be willing to absorb the unit supply of the asset or, in other words, the asset would trade at the intrinsic value $\left(p_{t}=V\right)$.

The arbitrageur is compensated in two ways in accord with actual practice - via an up-front "management fee" and an after-the-fact performancebased "incentive fee." 5 At the beginning of each period, he receives a fraction $(\alpha)$ of the assets under management, and at the end of the period he receives a fraction $(\beta)$ of any positive return on the portfolio. This corresponds to compensation structures in real-world hedge funds, where managers typically collect $\alpha=1$ percent or $\alpha=2$ percent of the equity capital, plus $\beta=20$ percent of any positive return on the fund's equity. We assume that the arbitrageur invests his entire fee income in the fund. This is because he recognizes the profitability of the fund's activities.

The variable $F_{t}$ denotes the total financial resources available to the arbitrageur at time $t$ $(t=1,2,3)$. The value of $F_{1}$ is exogenous, while the quantities $F_{2}$ and $F_{3}$ are determined in the model. The startup capital, $F_{1}$, is provided solely by the investors, while the arbitrageur acquires the share $\alpha$ in $F_{1}$ immediately as part of his compensation. The arbitrageur acquires additional equity at $t_{2}$ in the amount of a fraction $\alpha$ of the outsiders' share in $F_{2}$. Furthermore, the arbitrageur acquires equity in the fund through capital gains on his equity position and through his share $\beta$ in the capital gains on the outsiders' equity. The quantity $F_{3}$ is the fund's liquidation value. Note that the arbitrageur is both the general equity partner of the fund and its manager, receiving compensation from outside investors (limited partners) according to the fee schedule described above.

We assume that the fund raises equity capital only at the outset-at $t_{1}$. This assumption prevents the arbitrageur from diluting initial investors' equity stakes later on. Remember that the arbitrageur's compensation depends not only on the return on but also on the amount of the outsiders' equity capital under management. The arbitrageur therefore might have an incentive to raise fresh capital at $t_{2}$, particularly if he expects low returns in the second period. This would dilute the fund's existing investors' equity stakes. Thus, we assume (in keeping with typical hedge-fund arrangements) that the fund closes to new and existing investors after raising the initial capital. Reinvested capital gains are conse- quently the sole source of additional equity capital in the second period.

At time $t_{2}$, the price of the asset either reverts to $V$ or it does not. If the asset price is $V$ at $t_{2}$, the arbitrageur liquidates the fund and holds cash until $t_{3}$. If the asset price does not equal $V$ at $t_{2}$, the arbitrageur invests aggressively - albeit not all of the fund's cash -in the underpriced asset. This portfolio then generates a risk-free return because the asset price rises to $V$ at $t_{3}$ with certainty.

The arbitrageur's (that is, the hedge fund's) demand for the asset at the interim date, $t_{2}$, is given by

$$
Q A_{2}=\frac{D_{2}}{p_{2}}, 0 \leq D_{2} \leq F_{2},
$$

where $D_{2}$ is the amount of the hedge fund's demand in dollars. The amount $F_{2}-D_{2} \geq 0$ is held in cash. Because total demand aggregated across noise traders and the arbitrageur must equal the asset supply of one unit $\left(Q N_{2}+Q A_{2}=1\right)$, the price of the financial asset at $t_{2}$ is determined by combining (1) and (2):

$$
p_{2}=V-S_{2}+D_{2}, \quad 0 \leq D_{2}<S_{2} .
$$

The condition $D_{2}<S_{2}$ implies that the asset still trades at a discount to the intrinsic value at $t_{2}: p_{2}<V$. This assumption recognizes the arbitrageur's incentive not to bid up the price all the way to intrinsic value immediately - an implication of the fact that the arbitrageur will be compensated during the last period for achieving a positive return on investment.

As shown by Grossman and Vila (1992), the arbitrageur does not want to invest all of $F_{1}$ in the asset at $t_{1}$, either. After all, the asset may become even more underpriced at $t_{2}$, in which event he will want to increase his investment ("double up"). With $D_{1}$ denoting the amount the arbitrageur invests in the asset at $t_{1}$, we have

$$
Q A_{1}=\frac{D_{1}}{p_{1}}
$$

which implies the initial asset price will be

\footnotetext{
5 Amin and Kat (2001) report that hedge funds typically charge their investors a fixed annual "management fee" of 1 or 2 percent of assets under management plus an "incentive fee" of 15 to 25 percent of the fund's realized annual return. The incentive fee is waived if a particular "hurdle rate" has not been achieved, which can be a fixed number or a reference rate such as the T-bill rate plus or minus a spread. Most funds also apply a "high-water mark" provision, which requires the fund to make up any past losses before the incentive fee is paid. We assume the hurdle rate is zero, and we exclude any high-water mark for the sake of simplicity.
} 


$$
p_{1}=V-S_{1}+D_{1}, D_{1}<S_{1} .
$$

The condition $D_{1}<S_{1}$ implies $p_{1}<V$, which again captures the fact that the arbitrageur will not bid the price all the way up to the asset's intrinsic value because of the incentives built into his compensation schedule.

The investors have prior beliefs about the arbitrageur's talent in exploiting possible asset mispricing, but are not perfectly informed. Investors update their beliefs about the arbitrageur's talent using a simple Bayesian learning rule, which is based solely on the arbitrageur's past performance. When past returns are poor, investors don't know for sure whether the poor returns are due to a random error (noise), a deepening of noise trader misperception (bad luck), or truly inferior investment talent. Pulling some of their money from the hedge fund after the asset mispricing has deepened-that is, when the expected return on the long-short portfolio is highest-is the investor's rational response to the problem of inferring the arbitrageur's (unobservable) talent from data that are ambiguous (that is, observationally equivalent under more than one possible economic structure).

The investor's rule of updating his beliefs about the arbitrageur's talent implies that, if the hedge fund loses money during the first period, the fund faces withdrawals at the interim date, $t_{2}$. Specifically, we assume that the withdrawals at $t_{2}$ are a multiple of the hedge fund's posted gross return (that is, before management fees) at $t_{2}$, denoted $R_{2}$, should this return be negative. Remember that, while investors can withdraw capital, they cannot inject additional funds. Thus, the supply of funds in the second period is the following:

(6)

$$
F_{2}= \begin{cases}F_{1} \cdot \alpha \cdot\left(1+R_{2}\right)+F_{1} \cdot(1-\alpha) \cdot\left(1+R_{2}\right)^{\gamma}, \gamma>1, & \text { if }-1 \leq R_{2}<0 \\ F_{1} \cdot\left(1+R_{2}\right), & \text { if } R_{2}>0,\end{cases}
$$

where $\gamma$ is a parameter that determines the responsiveness of the investor to past performance. For $\gamma=1$, poor first-period returns do not shake the confidence of investors in the arbitrageur's talent. At the other extreme, responsiveness that becomes unboundedly large implies that even a small firstperiod loss is multiplied into a huge withdrawal of funds. Note that the outside investors may withdraw only what is theirs. This means that, even if the outsiders pull all of their money, the arbitrageur's equity stake remains and the fund can stay in business.
The arbitrageur knows that-despite a temporary deepening of the mispricing - the price of the asset will revert to intrinsic value at $t_{3}$ for certain, so he will keep his own money invested, come what may.

Our multiplicative feedback rule provides the arbitrageurs with what may be a more realistic incentive structure than the linear feedback rule in Shleifer and Vishny (1997). Our feedback rule does not penalize small negative returns quite as severely for a high degree of responsiveness, $\gamma$, as is the case in Shleifer and Vishny. For a responsiveness coefficient of $\gamma=5$, for instance, a gross return in the first period, $R_{2}$, of -1 percent reduces the fund's equity capital by approximately 4 percentage points. A 5 percent loss, on the other hand, leaves the fund with approximately 77 percent of its equity capital at the beginning of the next period. We provide more results from the model below.

The gross return of the hedge fund in the first period, $R_{2}$, is given by

$$
R_{2}=\frac{\left(F_{1}-D_{1}\right)+D_{1} \cdot \frac{p_{2}}{p_{1}}-F_{1}}{F_{1}}=\frac{D_{1} \cdot \frac{p_{2}-p_{1}}{p_{1}}}{F_{1}} .
$$

The fund's first-period return consists of its return on the financial asset, normalized by the total funds available for investment.

For simplicity, we assume a specific form of uncertainty about noise trader sentiment at $t_{2}, S_{2}$. With probability $1-q(0<q<1)$, noise traders recognize the true value of the asset, which implies $S_{2}=0$. In this case, the arbitrageur liquidates at $t_{2}$ and holds cash until $t_{3}$. Then the arbitrageur's assets under management at $t_{3}$ would amount to

$$
F_{3}^{S_{2}=0}=F_{2}^{S_{2}=0} \equiv F_{1} \cdot\left(1+R_{2}^{S_{2}=0}\right),
$$

where

$$
R_{2}^{S_{2}=0}=\frac{\left(F_{1}-D_{1}\right)+D_{1} \cdot \frac{V}{p_{1}}-F_{1}}{F_{1}} .
$$

On the other hand, noise trader misperception deepens to $S_{2}$ with probability $q, S_{2}=S>S_{1}(>0)$. If noise traders continue to misperceive the intrinsic value of the asset, the hedge fund's assets at $t_{3}$ will amount to the following:

\footnotetext{
6 Some hedge funds have "lock-up" periods of one to three years, while others allow investors to withdraw money with only a few weeks' notice. As a result of the poor quality of investors' information about the arbitrageur's talent, the arbitrageur's past performance often is a major determinant of the resources he receives to manage, regardless of the actual arbitrage opportunities available to him.
} 


$$
\begin{aligned}
F_{3}^{S_{2}=S} & =\frac{V}{p_{2}^{S_{2}=S}} \cdot D_{2}+\left(F_{2}^{S_{2}=S}-D_{2}\right) \\
& =\frac{V}{p_{2}^{S_{2}=S}} \cdot D_{2}+F_{1} \cdot\left(1+R_{2}^{S_{2}=S}\right) \gamma-D_{2},
\end{aligned}
$$

where

$$
R_{2}^{S_{2}=S}=\frac{\left(F_{1}-D_{1}\right)+D_{1} \cdot \frac{p_{2}^{S_{2}=S}}{p_{1}}-F_{1}}{F_{1}} .
$$

\section{THE ARBITRAGEUR'S OPTIMIZATION PROGRAM}

The arbitrageur's total income consists of management fees and capital gains on reinvested management fees. The expected value of the management fees, $M F$, equals the sum of the expected values of the management fees collected at $t_{1}\left(M F_{1}\right)$, at $t_{2}\left(M F_{2}\right)$, and at $t_{3}\left(M F_{3}\right)$. The expected value of the capital gains is $C G$. The arbitrageur's maximization problem therefore is

$$
\underset{D_{1}, D_{2}}{\operatorname{Max}}\left\{M F_{1}+M F_{2}+M F_{3}+C G\right\}
$$

where the management fees are

$$
\begin{gathered}
M F_{1}=\alpha \cdot F_{1}, \\
M F_{2}=M F_{2}^{S_{2}=S}+M F_{2}^{S_{2}=0}, \text { and } \\
M F_{3}=\beta \cdot q \cdot R_{3}^{S_{2}=S} \\
\cdot\left(F_{2}^{S_{2}=S}-\left(1+R_{2}^{S_{2}=S}\right) \cdot M F_{1}-M F_{2}^{S_{2}=S}\right)
\end{gathered}
$$

and where

$$
\begin{aligned}
& M F_{2}^{S_{2}=S}= \alpha \cdot q \cdot\left(F_{2}^{S_{2}=S}-\alpha \cdot\left[1+R_{2}^{S_{2}=S}\right] \cdot F_{1}\right. \\
&\left.-\beta \cdot \max \left\{0, R_{2}^{S_{2}=S}\right\} \cdot(1-\alpha) \cdot F_{1}\right) \\
&+\beta \cdot q \cdot \max \left\{0, R_{2}^{S_{2}=S}\right\} \cdot(1-\alpha) \cdot F_{1}, \\
& M F_{2}^{S_{2}=0}= \alpha \cdot(1-q) \cdot\left(F_{2}^{S_{2}=0}-\alpha \cdot\left[1+R_{2}^{S_{2}=0}\right] \cdot F_{1}\right. \\
&\left.-\beta \cdot R_{2}^{S_{2}=0} \cdot(1-\alpha) \cdot F_{1}\right) \\
&+\beta \cdot(1-q) \cdot R_{2}^{S_{2}=0} \cdot(1-\alpha) \cdot F_{1}, \text { and } \\
& R_{3}^{S_{2}=S}=\frac{\left(F_{2}^{S_{2}=S}-D_{2}^{S_{2}=S}\right)+D_{2}^{S_{2}=S} \cdot \frac{V}{p_{2}^{S_{2}=S}-F_{2}^{S_{2}=S}}}{F_{2}^{S_{2}=S}} .
\end{aligned}
$$

The quantity $M F_{2}{ }_{2}{ }^{2}=S$ represents the income the arbitrageur collects at $t_{2}$ should the noise traders' misperception deepen in the first period, while $M F_{2}{ }^{S_{2}=0}$ is the fee income if the asset price reverts to intrinsic value. The arbitrageur also captures capital gains on the equity he builds from the reinvested management fees. The expected value of the capital gains, $C G$, equals

(14)

$$
\begin{aligned}
C G= & q \cdot\left(R_{2}^{S_{2}=S} \cdot M F_{1} \cdot\left[1+R_{3}^{S_{2}=S}\right]+R_{3}^{S_{2}=S} \cdot M F_{2}^{S_{2}=S}\right) \\
& +(1-q) \cdot R_{2}^{S_{2}=0} \cdot M F_{1} .
\end{aligned}
$$

The arbitrageur's choice variables are $D_{1}\left(\leq F_{1}\right)$ and $D_{2}\left(\leq F_{2}^{S_{2}=S}\right)$, which are the amounts the arbitrageur invests in the asset at $t_{1}$ and $t_{2}$, respectively. Unless the asset reverts to intrinsic value at $t_{2}\left(p_{2}=V\right)$, the $t_{2}$ price of the asset given in equation (3) is a function of the $t_{2}$ choice variable, $D_{2}$. Similarly, the $t_{1}$ price of the asset given in equation (5) is a function of the choice variable, $D_{1}$.

\section{SOLUTION TO THE MAXIMIZATION PROBLEM}

We solve the maximization problem numerically. We hold constant all of the following: $V=1$; $F_{1}=S_{1}=0.2 ; S_{2}=0.4 ; q=1-q=0.5 ; \alpha=0.02$; and $\beta=0.2$. Note that $F_{1}=S_{1}=0.2$ means that the arbitrageur has sufficient buying power to eliminate the $t_{1}$ mispricing entirely if so desired. Also, note that $0.4=S_{2}>S_{1}=0.2$ means that noise trader misperception may deepen between $t_{1}$ to $t_{2}$-that is, the asset may become even more mispriced. For the values chosen for $S_{1}, S_{2}$, and $q$, noise trader misperception, $S$, is as likely to double as it is to vanish. Thus, the expected value of noise trader misperception in the second period, $q \cdot S_{2}$, equals the noise trader misperception observed in the first period, $S_{1}$.

We vary $\gamma$, the responsiveness to past performance of fund withdrawals, from $\gamma=1$ (no responsiveness by the investors to past investment performance, that is, no withdrawals) to $\gamma=20$ (extreme responsiveness) with a step length of unity. We use a grid search method to solve the maximization problem. This involves varying $D_{1}$ and $D_{2}$ independently in very small increments within their bounds, $0 \leq D_{i} \leq$ $F_{i}(i=1,2)$, to find the maximum of the objective function.

The findings of the grid search are displayed in Figures 2 through 5 . The first important point to make concerns the extent to which the presence of the hedge fund affects asset mispricing. Figure 2 shows that the mispricing is less pronounced in each period than it would be without the hedge fund. 


\section{Figure 2}

\section{Effect of Investor Responsiveness on Asset Prices}

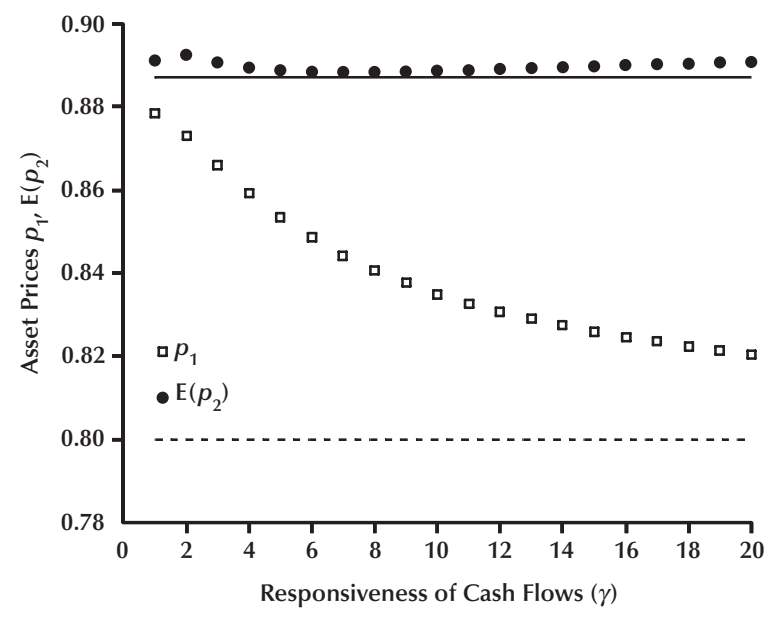

Remember that, without arbitrage, the first-period price, $p_{1}$, and the expected value of the second-period price, $\mathrm{E}\left[p_{2}\right]$, both would equal 0.8 (shown as a dashed line). On the other hand, without noise traders, the asset would trade at unit value in both periods (not shown). The hedge fund almost halves the difference between the expected value of the second-period price, $\mathrm{E}\left[p_{2}\right]$ (shown as solid circles), and the asset's intrinsic, unit value. In fact, the degree of investor responsiveness, $\gamma$, has little bearing on $\mathrm{E}\left[p_{2}\right]$, which approaches the value of approximately 0.8873 (shown as a solid horizontal line) as $\gamma$ approaches infinity. By comparison, the degree of responsiveness has a strong impact on the first-period price, $p_{1}$ (shown as open boxes). This is because the arbitrageur treads even more cautiously when putting on this trade in the first period when he knows that the investors penalize negative returns with sizeable withdrawals. In fact, the higher is $\gamma$, the more cash the arbitrageur holds in the first period, and therefore, the lower is $p_{1}$. As the degree of investor responsiveness, $\gamma$, goes to infinity, the amount the arbitrageur invests in the first period goes to zero and, consequently, the first-period price, $p_{1}$, converges to $0.8-$ the value the asset would adopt if there were no hedge fund in the market (shown as a dashed line). Thus we conclude that the hedge fund pushes the price of the asset (or its respective expected value) toward the intrinsic, unit value in both periods. This is our first main finding.

\section{Figure 3}

\section{Effect of Investor Responsiveness on Asset Price Volatility}

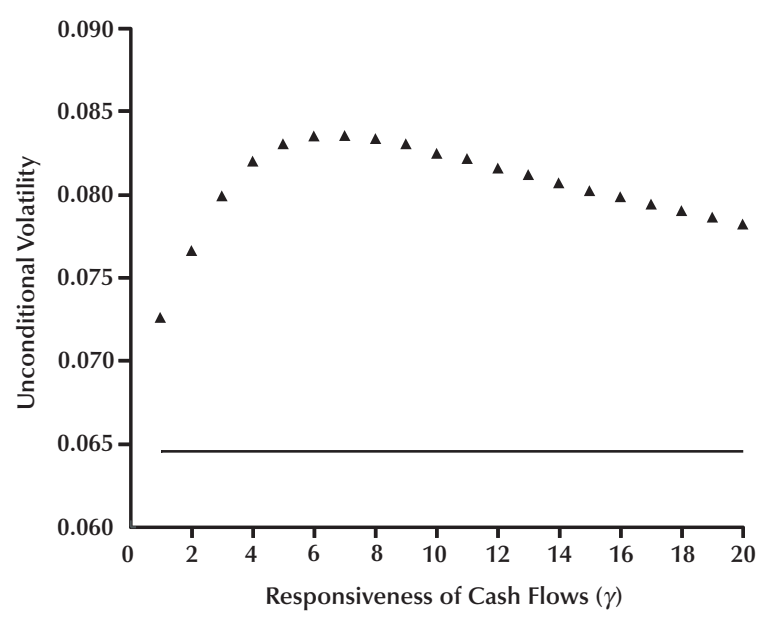

Figure 3 shows the unconditional volatility of the asset's returns for various degrees of investor responsiveness, $\gamma$. The unconditional volatility is calculated as the expected value of the squared returns over the two periods. For low values of investor responsiveness, volatility increases as $\gamma$ increases. For high values of responsiveness, a further increase in $\gamma$ reduces volatility monotonically. As $\gamma$ goes to infinity, volatility approaches a level (as shown by the solid line) that is lower than the volatility level at $\gamma=1$ (as indicated by the leftmost symbol), which is the benchmark case of unwavering investor confidence in the hedge fund manager. The reason for this "volatility hump" lies in the existence of two opposite effects. All else equal, the higher $\gamma$ is, the bigger is the drop in the asset's price from $t_{1}$ to $t_{2}$ should the noise traders' misperception deepen. On the other hand, the higher $\gamma$ is, the lower is the price of the asset at $t_{1}$ because the arbitrageur puts less money to work. For low values of investor responsiveness, the volatility-increasing effect dominates. For increasingly higher values of $\gamma$, this effect becomes progressively weaker until it vanishes for an infinitely large degree of investor responsiveness.

It is important to note that the hedge fund greatly reduces asset price volatility, regardless of the degree of investor responsiveness. The unconditional volatility without the hedge fund runs at 0.5694 (not shown), which is a multiple of the volatility that we observe even at the degree of responsive- 


\section{Figure 4}

\section{Effect of Investor Responsiveness on Asset Return When Misperception Deepens}

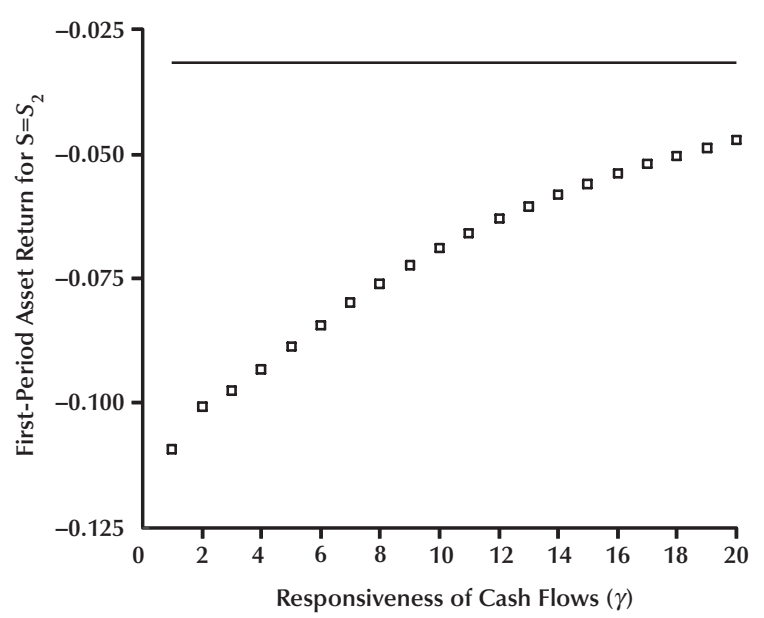

ness that generates the highest level of volatility. Thus, we conclude that the hedge fund unambiguously reduces unconditional volatility. This is our second main finding.

Another way to look at the impact of arbitrage on volatility is to ask how the market behaves when asset mispricing deepens. Such an event-if severemight cause, or occur alongside, a financial crisis. Figure 4 shows, for the case of a deepening noise trader misperception of the asset's intrinsic value, the first-period asset return as a function of investor responsiveness. The absolute value of the percentage decline of the asset price increases with investor responsiveness, $\gamma$. For an infinitely high value of $\gamma$, the arbitrageur holds cash in the first period and then invests aggressively at $t_{2}$, although he does not invest all the cash available. The horizontal line in Figure 4 signifies the first-period return for this borderline case of an infinite degree of responsiveness. Note that, without a hedge fund, the first-period return would amount to a negative 25 percent (not shown), which is more than twice as much (in absolute value) as what is observed even with a degree of responsiveness of zero (that is, $\gamma$ equal to one). Hence, we conclude that the presence of a hedge fund dampens volatility in the event of a deepening of noise trader misperception, as might occur in a financial panic. This is our third main finding.

Finally, we are interested in the question of how investor responsiveness affects the arbitrageur's

\section{Figure 5}

Effect of Investor Responsiveness on Arbitrageur's Profit

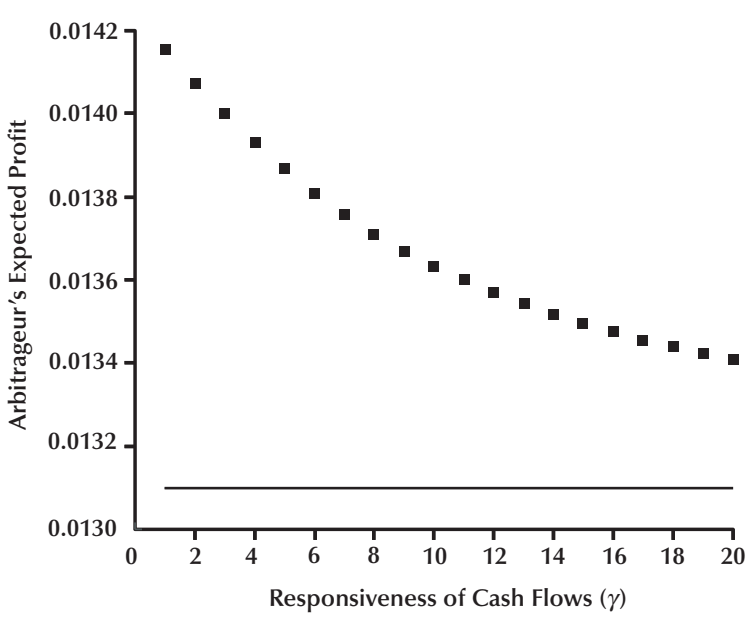

profit, that is, his incentive to set up a hedge fund and engage in arbitrage. Figure 5 shows the arbitrageur's profit as a function of $\gamma$. Not surprisingly, the profit of the arbitrageur decreases monotonically with increased investor responsiveness to past performance. The monotonic decline in the profitability of arbitrage with increasing investor responsiveness to past performance is a manifestation of the fact that liquidating a hedge portfolio when the expected return from arbitrage is highest is counterproductive - that is, it runs against "the nature of the trade."

\section{CONCLUSION}

Even financially constrained professional arbitrageurs may be able to exploit asset mispricing if they can link up with rational but uninformed investors. To achieve this goal, the two parties must overcome - at least to a degree - the problem of asymmetric information about the arbitrageur's talent. The result of such an endeavor is a hedge fund that goes long on (comparatively) underpriced assets and short on (comparatively) overpriced assets. As a byproduct, the impacts of noise trader misperceptions on asset prices and volatility are reduced. This holds for any degree of responsiveness to past performance ("feedback") of the investors' confidence in the arbitrageur's talent.

This article builds on the dynamic-investment literature that reaches back at least to Merton (1971). 
Shleifer and Vishny (1997) provided an insightful model of wealth-constrained arbitrageurs that can be, and has been, extended in several directions. We add several realistic features to the professional arbitrageur's problem in the canonical model, including the ability to build an equity stake in his hedge fund over time, and a potentially more realistic multiplicative (rather than linear) investor feedback rule. Like Shleifer and Vishny, we assume that the hedge fund can influence the market price. Hedge funds do, in fact, sometimes move market prices because they operate in specialized market segments that have limited liquidity. It is also true, however, that hedge funds alone cannot prevent asset-price volatility or occasional mispricing-which might deepen before it eventually corrects.

\section{REFERENCES}

Amin, Guarav S. and Kat, Harry M. "Hedge Fund Performance 1990-2000: Do the 'Money Machines' Really Add Value?” Working paper, University of Reading (UK), 15 May 2001.

Breedon, Douglas T. “An Intertemporal Asset Pricing Model with Stochastic Consumption and Investment Opportunities." Journal of Financial Economics, September 1979, 7(3), pp. 265-96.

Campbell, John Y.; Lo, Andrew and MacKinlay, A. Craig. The Econometrics of Financial Markets. Princeton, N.J.: Princeton University Press, 1997.

and Viceira, Luis M. "Consumption and Portfolio Decisions When Expected Returns Are Time Varying." Quarterly Journal of Economics, May 1999, 114(2), pp. 433-95.

Fama, Eugene F. “The Behavior of Stock Market Prices.” Journal of Business, 1965, 38, pp. 34-105.

Friedman, Milton. "The Case for Flexible Exchange Rates," in Essays in Positive Economics. Chicago: University of Chicago Press, 1953.

Gromb, Denis and Vayanos, Dimitri. "Equilibrium and Welfare in Markets with Financially Constrained Arbitrageurs."
Working paper, London Business School and Massachusetts Institute of Technology, October 2001.

Grossman, Sanford J. and Vila, Jean-Luc. "Optimal Dynamic Trading with Leverage Constraints." Journal of Financial and Quantitative Analysis, June 1992, 27(2), pp. 151-68.

and Zhou, Zhongquan. "Equilibrium Analysis of Portfolio Insurance.” Journal of Finance, September 1996, 51(4), pp. 1379-1403.

Keynes, John Maynard. The General Theory of Employment, Interest, and Money. New York: Harcourt, Brace \& World, 1936.

Kyle, Albert S. and Xiong, Wei. "Contagion as a Wealth Effect.” Journal of Finance, August 2001, 56(4), pp. 1401-40.

Merton, Robert C. "Optimal Consumption and Portfolio Rules in a Continuous-Time Model." Journal of Economic Theory, December 1971, 3(4), pp. 373-413.

"An Intertemporal Capital Asset Pricing Model." Econometrica, September 1973, 41(5), pp. 323-61.

Muth, J. "Optimal Properties of Exponentially Weighted Forecasts." Journal of the American Statistical Association, 1960, 55, pp. 299-306.

Samuelson, Paul. "Proof That Properly Anticipated Prices Fluctuate Randomly.” Industrial Management Review, 1965, 6, pp. 41-49.

Scholes, Myron S. "Crisis and Risk Management." American Economic Review Papers and Proceedings, May 2000, 90(2), pp. 17-21.

Sharpe, William P. and Alexander, Gordon. Investments. 4th Edition. Englewood Cliffs, N.J.: Prentice Hall, 1990.

Shleifer, Andrei and Vishny, Robert W. "The Limits of Arbitrage.” Journal of Finance, March 1997, 52(1), pp. 35-55.

Xiong, Wei. "Convergence Trading with Wealth Effects: An Amplification Mechanism in Financial Markets." Journal of Financial Economics, November 2001, 62(2), pp. 247-92. 
